chestnut and maple leaves. J. Photochem. Photobiol. Biol., 1994 22, 247-252.

20. Hunt Jr, E. R., Doraiswamy, P. C., McMurtrey, J. E., Daughtry, C. S., Perry, E. M. and Akhmedov, B., A visible band index for remote sensing leaf chlorophyll content at the canopy scale. Int. $J$. Appl. Earth Observ. Geoinf., 2013, 21, 103-112.

21. Huete, A. R., A soil-adjusted vegetation index (SAVI). Remote Sensing Environ., 1988, 25, 295-309.

22. Gitelson, A. A., Gritz, Y. and Merzlyak, M. N., Relationships between leaf chlorophyll content and spectral reflectance and algorithms for non-destructive chlorophyll assessment in higher plant leaves. J. Plant Physiol., 2003, 160, 271-282.

23. Daughtry, C., Walthall, C., Kim, M., De Colstoun, E. B. and McMurtrey Iii, J., Estimating corn leaf chlorophyll concentration from leaf and canopy reflectance. Remote Sensing Environ., 2000, 74, 229-239.

24. Haboudane, D., Miller, J. R., Tremblay, N., Zarco-Tejada, P. J. and Dextraze, L., Integrated narrow-band vegetation indices for prediction of crop chlorophyll content for application to precision agriculture. Remote Sensing Environ., 2002, 81, 416-426.

25. Verrelst, J. et al., Quantifying vegetation biophysical variables from imaging spectroscopy data: a review on retrieval methods. Surveys Geophys., 2018, 40(3), 1-41.

26. Tipping, M. E. (ed.), Bayesian inference: An introduction to principles and practice in machine learning. In Advanced Lectures on Machine Learning, Springer, 2004, pp. 41-62.

27. Cawley, G. C., Talbot, N. L. and Chapelle, O., Estimating predictive variances with kernel ridge regression. In Machine Learning Challenges Workshop, 2005, pp. 56-77.

28. Saunders, C., Gammerman, A. and Vovk, V., Ridge regression learning algorithm in dual variables. In ICML '98 Proceeding of the Fifteenth International Conference on Machine Learning, 1998, pp. 515-521.

29. Belgiu, M. and Drăguț, L., Random forest in remote sensing: A review of applications and future directions. ISPRS J. Photogramm. Remote Sensing, 2016, 114, 24-31.

30. Walton, J. T., Subpixel urban land cover estimation. Photogramm. Eng. Remote Sensing, 2008, 74, 1213-1222.

31. Gitelson, A. A. and Merzlyak, M. N., Remote sensing of chlorophyll concentration in higher plant leaves. Adv. Space Res., 1998, 22, 689-692.

32. Jones, C. L., Weckler, P., Maness, N. O., Jayasekara, R., Stone, M. and Chrz, D., Remote sensing to estimate chlorophyll concentration in spinach using multi-spectral plant reflectance. Trans. ASABE, 2007, 50, 2267-2273.

33. Hunt, E. R., Cavigelli, M., Daughtry, C. S., Mcmurtrey, J. E. and Walthall, C. L., Evaluation of digital photography from model aircraft for remote sensing of crop biomass and nitrogen status. Precis. Agric., 2005, 6, 359-378.

34. Peng, Y., Huang, H., Wang, W., Wu, J. and Wang, X., Rapid detection of chlorophyll content in corn leaves by using least squares-support vector machines and hyperspectral images. $J$. Jiangsu Univ.-Natural Sci. Edn, 2011, 32, 125-174.

35. Verrelst, J., Rivera, J. P., Gitelson, A., Delegido, J., Moreno, J. and Camps-Valls, G., Spectral band selection for vegetation properties retrieval using Gaussian processes regression. Int. J. Appl. Earth Observ. Geoinform., 2016, 52, 554-567.

ACKNOWLEDGEMENTS. The authors thank the UAV team of NESAC (Shillong) and ICAR (Shillong) for their help in carrying out field data collection and analysis. The experimental research was funded by Department of Science and Technology (DST), New Delhi under the project 'Characterization of acid soils under different land uses and its impact on crop growth: a hyperspectral approach' (Grant Number: DST-BDID/01/23/2014 - HSRS dated 18.03.2016).

Received 2 June 2019; revised accepted 24 July 2019

doi: $10.18520 / \mathrm{cs} / \mathrm{v} 117 / \mathrm{i} 11 / 1874-1879$

\section{Fate and transport of microplastics from water sources}

\author{
Monnisha Ganesan ${ }^{1}$, Gobi Nallathambi ${ }^{1, *}$ and \\ Seshachalam Srinivasalu ${ }^{2}$ \\ ${ }^{1}$ Department of Textile Technology, and \\ ${ }^{2}$ Department of Geology, Institute of Ocean Management, \\ Anna University, Chennai 600 025, India
}

Microplastics as environmental pollutants affect surface water and groundwater. Surface water, groundwater and branded drinking water bottles were analysed in and around Chennai, Tamil Nadu, India. The total count of microplastics was found to be 66 particles with fibrous and fragmented shape, colours such as white, blue, green, yellow, pink and black under optical microscope. SEM-EDX-used to study morphology and elemental analysis of microplastics confirmed the presence of heavy metals such as $\mathrm{Cr}$, $\mathbf{T i}$, Mo, Ba and Ru adhered to their surface. Polyethylene terephthalate and polyamide were confirmed by the presence of functional groups of the polymers by FTIR equipped with attenuated total reflectance.

Keywords: Microplastics, heavy metals, pollution, polyamide, water sources.

PLASTICS are synthetic organic polymers formed by the process of polymerization ${ }^{1}$. The use of plastics has increased worldwide and the annual production is around 322 million metric tonnes ${ }^{2}$. In India, approximately 5.6 million tonnes $(\mathrm{mt})$ of plastic waste is generated annually ${ }^{3}$. Plastic debris which is less than $5 \mathrm{~mm}$ is referred to as microplastic, and categorized as primary and secondary. The main sources of microplastics in the marine environment are land and sea-based litter ${ }^{4}$. Microplastics are a big threat to marine organisms as they are ingested by them. A study was done on the distribution, weathering and chemical characteristics of microplastics on the beaches of Goa, India during the southwest and northeast monsoon seasons ${ }^{4}$. The distribution and characteristics of microplastic pollution along the coast of Chennai, Tamil Nadu (TN), India during pre- and post-flood were also studied $^{5}$. Presence of microplastics and their distribution and characteristics were reported from Rameswaram Coral Island, TN, India ${ }^{6}$, marine water from Kuala Nerus and Kuantan Port in Malaysia $^{7}$, drinking water treatment plants in Germany ${ }^{8}$, freshwater resources like Vembanad lake in Kerala ${ }^{3}$, Huron Lake in Canada ${ }^{9}$, and three urban estuaries in China ${ }^{10}$. Microplastics were also identified in bottled drinking water, because of the packaging materials (polyethylene terephthalate), which are consumed by humans ${ }^{11}$. In India, only a few studies are available on microplastics contamination in sediment samples of

*For correspondence. (e-mail: gobsnn@gmail.com) 


\section{RESEARCH COMMUNICATIONS}

\begin{tabular}{lclr}
\hline Location & Sample type & Microplastics & Reference \\
\hline $\begin{array}{l}\text { Chennai coast } \\
\text { Goa coast }\end{array}$ & Sediment & Polyethylene and polypropylene & 5 \\
$\begin{array}{l}\text { Coast of Chennai and Tinnakkara Island } \\
\text { Vembanad lake }\end{array}$ & $\begin{array}{l}\text { Sediment } \\
\text { Polyethylene and polypropylene }\end{array}$ & 4 \\
Rameswaram Coral Island & Sediment & $\begin{array}{c}\text { Not identified } \\
\text { High-density polyethylene, low-density } \\
\text { polyethylene, polypropylene and polystyrene }\end{array}$ \\
Five coastal areas of Tamil Nadu & Sediment & $\begin{array}{c}\text { Polypropylene, polyethylene, polystyrene, } \\
\text { polyvinylchloride and nylon }\end{array}$ \\
& Sediment & $\begin{array}{c}\text { Polyethylene, polypropylene, polyamider, polyester } \\
\text { and polystyrene }\end{array}$ & 6 \\
\hline
\end{tabular}

Figure 1. Microplastic contamination reported in India.

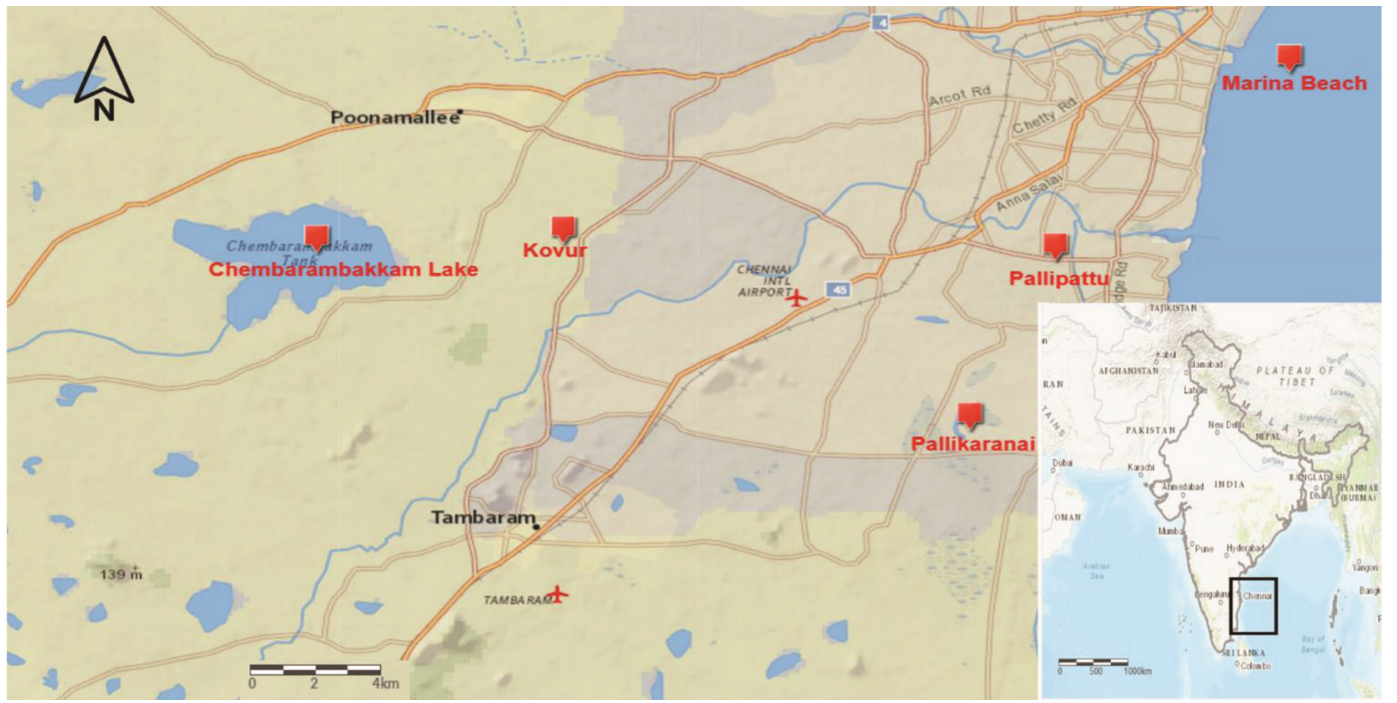

Figure 2. Sampling location in Chennai, Tamil Nadu, India ${ }^{18}$

marine and freshwater/estuaries, and no study has addressed the presence of microplastics in groundwater and packaged drinking water. Hence, the present study was conducted in and around Chennai, to identify microplastics from various sources of water. Figure 1 provides a summary of microplastic contamination in India.

Chennai is situated along the Bay of Bengal coast and its total population is around 10 million. Water samples were collected during March 2019 from different places like Marina seawater (M), Pallikaranai (P) and Kovur (K) groundwater, Chembarambakkam Lake (CL) surface water which is the drinking water source for Chennai city, Pallipattu from where the water (groundwater) is supplied for domestic purposes (PP), can water from domestic suppliers $(\mathrm{C} ; 25 \mathrm{l})$ and branded drinking water bottles (B1, B2, B3, B4 and B5). Surface and groundwater samples were collected in glass bottles and taken directly to the laboratory for further examination. Figure 2 shows the sampling location.

Equal volume (1 litre) of water from each sample was filtered using vacuum filtration set-up with $0.45 \mu \mathrm{m}$ Whatman cellulose nitrate filter paper and dried at room temperature for further analysis. The dried filter paper containing the microplastics was placed under an optical microscope at 40× magnification (Labomed LX-300, USA), equipped with a digital camera. Particles identified as microplastics were analysed for physical characteristics such as shape, colour and count. Morphological and elemental analyses of the particles were performed using a scanning electron microscope (SEM) equipped with an energy dispersive X-ray (EDX) analyser (Hitachi S-3400, USA). EDX analysis was performed at low vacuum with an operating voltage of $15 \mathrm{kV}$. Microplastics were then examined using Fourier transform infrared spectroscopy (FTIR) equipped with attenuated total reflectance (JASCO 6600typeA, Easton, USA).

The number of microplastics was found to be 66 from eleven water samples. Fibrous and fragment shaped microplastics were found, with fragment shaped ones being dominant. White, green, yellow, brown, blue, pink and black were the colours identified. Figures 3 and 4 show the colour and count of microplastics present in each sample. Figure 5 highlights the factors causing microplastic contamination. 
RESEARCH COMMUNICATIONS

Table 1. Nature of microplastics and their confirmation

\begin{tabular}{|c|c|c|c|c|}
\hline $\begin{array}{l}\text { Sample } \\
\text { Id }\end{array}$ & Dominant microplastic image & $\begin{array}{c}\text { Fourier transform } \\
\text { infrared spectroscopy }\end{array}$ & $\begin{array}{l}\text { Scanning electron } \\
\text { microscope }\end{array}$ & $\begin{array}{c}\text { energy dispersive } \\
\text { EDX }\end{array}$ \\
\hline
\end{tabular}

Surface water
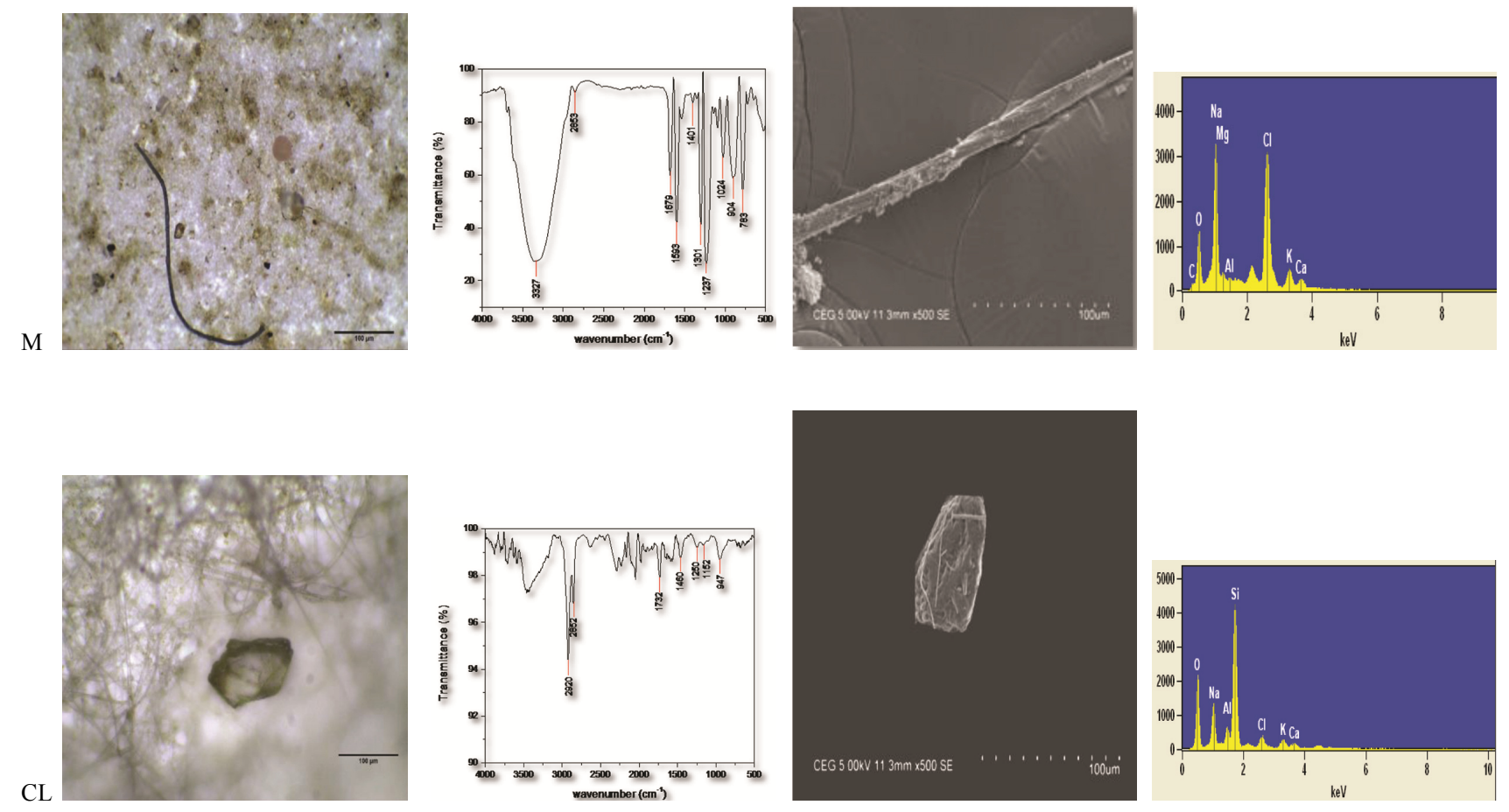

Ground water
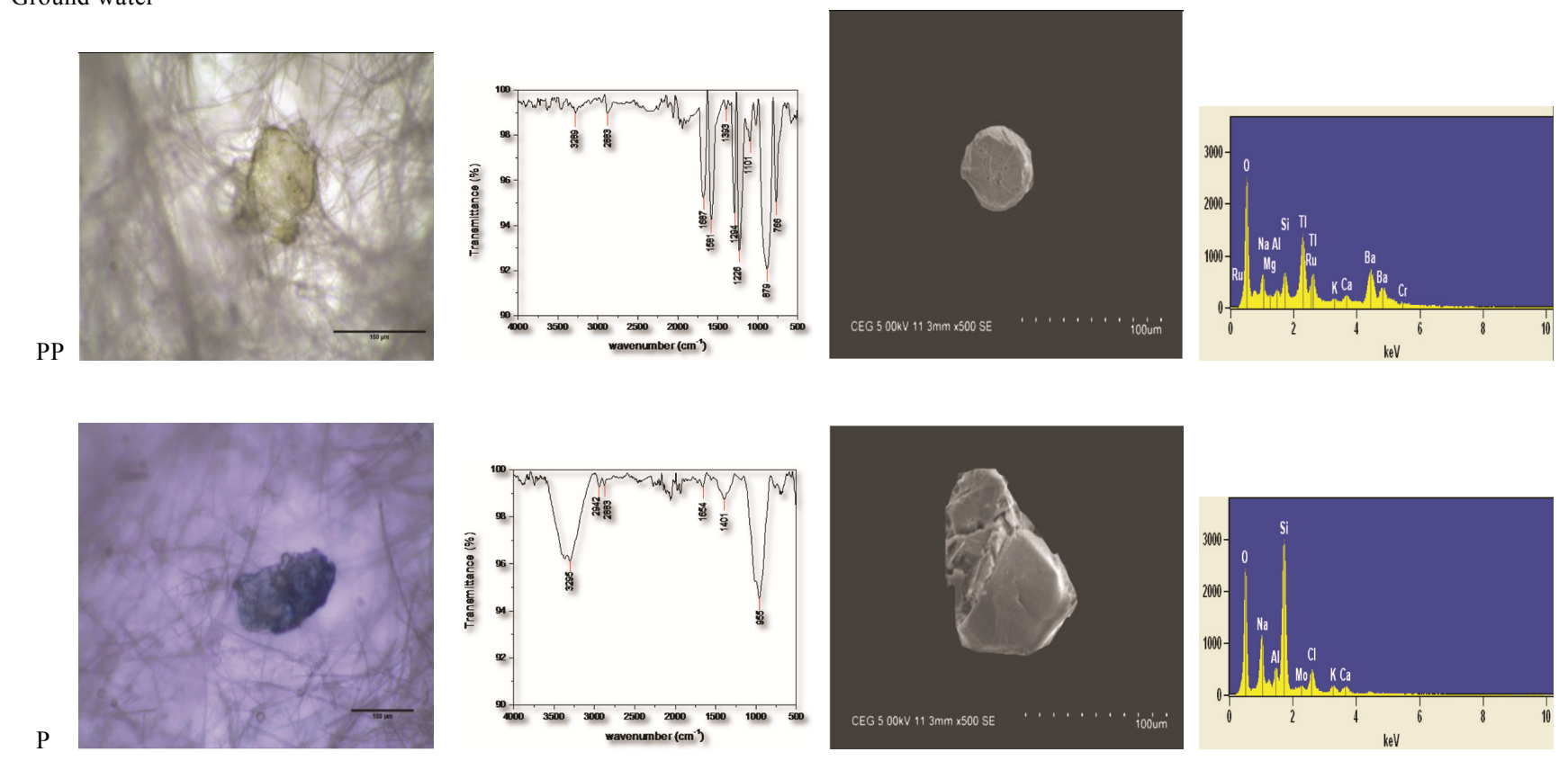

$($ Contd $)$ 
Table 1. (Contd)

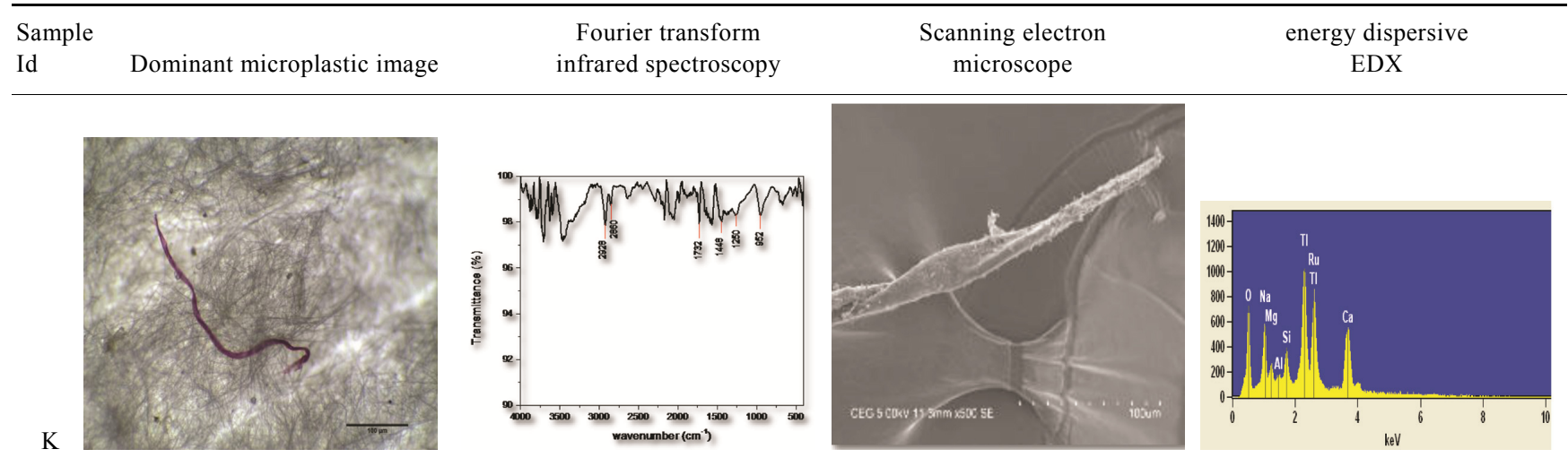

Commercial drinking water
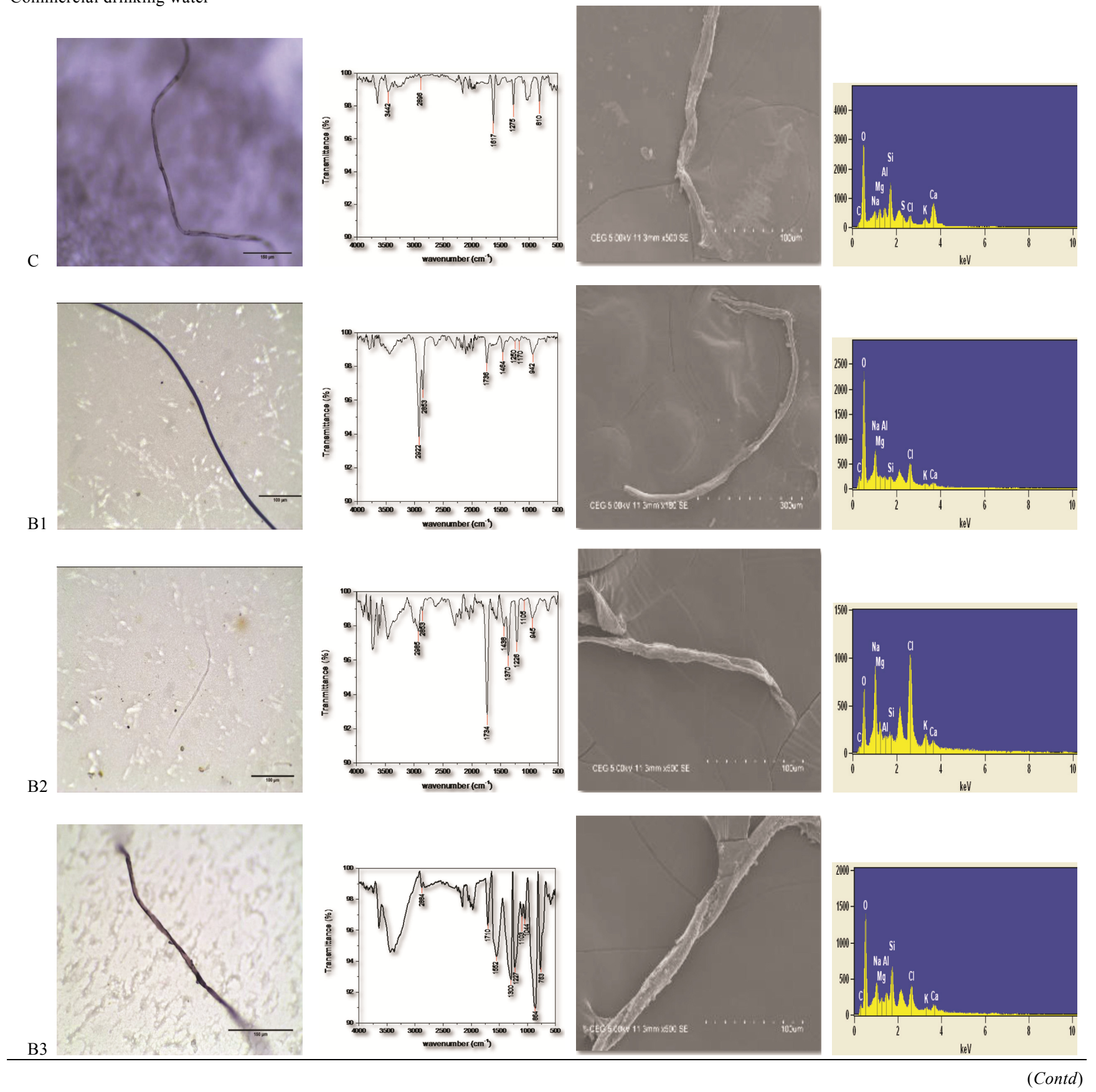
Table 1. (Contd)
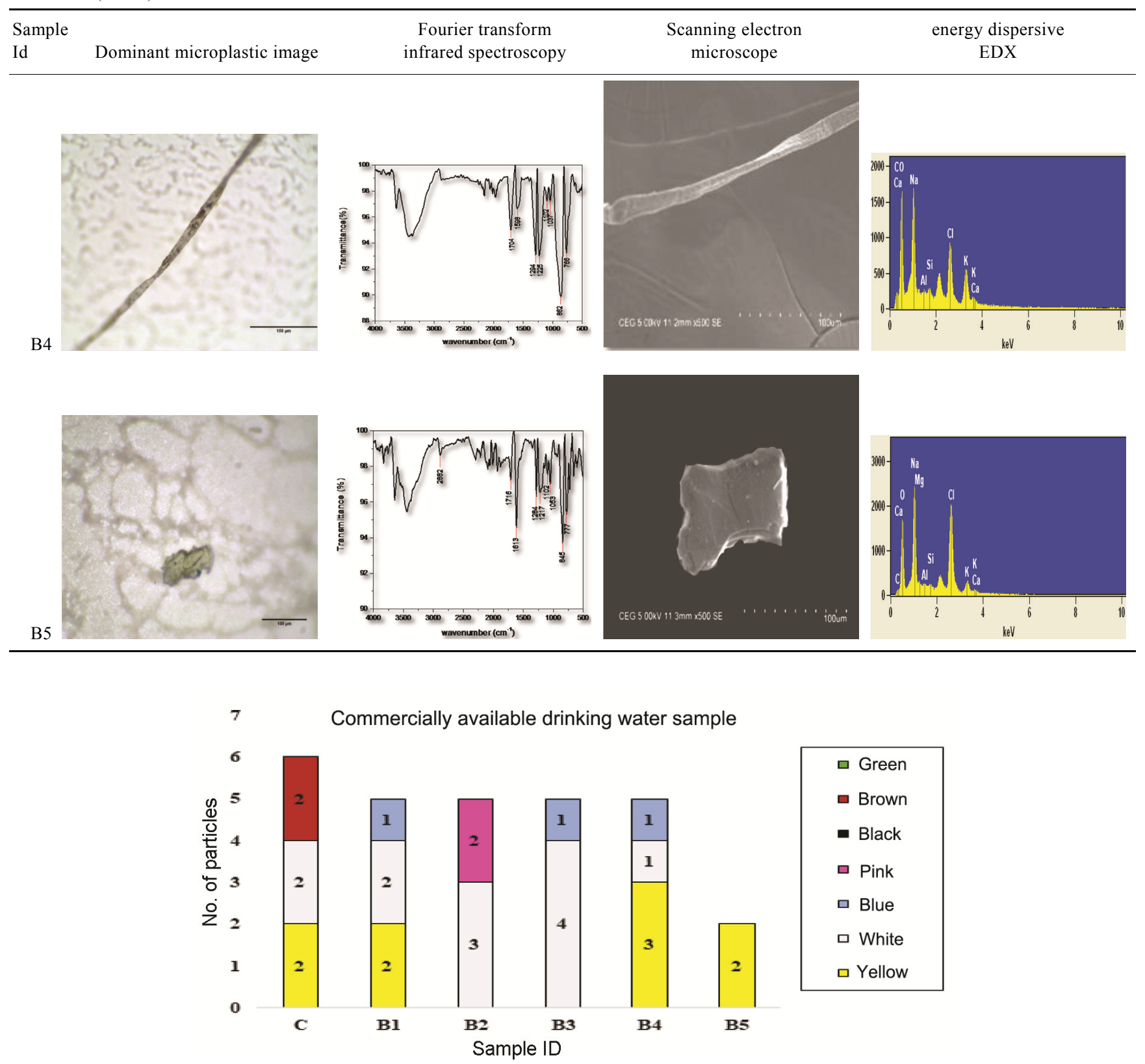

Figure 3. Colour classification of microplastics in commercially available drinking water.

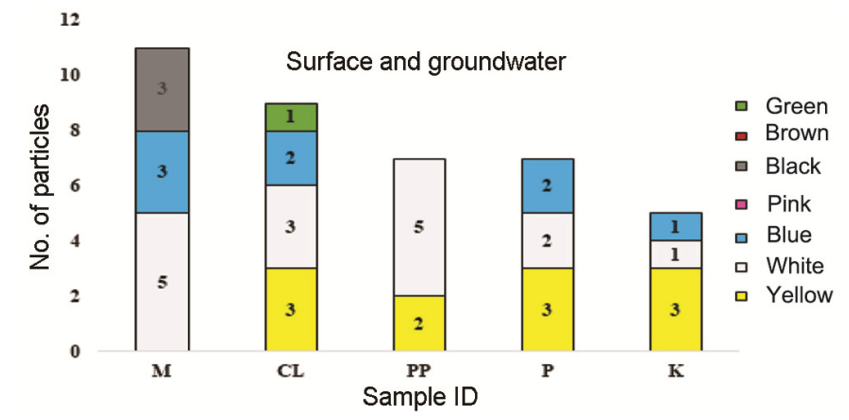

Figure 4. Colour classification of microplastics in groundwater and surface water.
FTIR confirms microplastics by the presence of functional groups of the polymer. For polyethylene terephthalate, the absorption bands were observed at $\mathrm{C}=\mathrm{O}$ stretch around $1716 \mathrm{~cm}^{-1}, \mathrm{CH}_{2}$ stretching around $2882 \mathrm{~cm}^{-1}$, $\mathrm{C}=\mathrm{C}$ stretch around $1580 \mathrm{~cm}^{-1}$ and additional peaks around 745 and $865 \mathrm{~cm}^{-1} \mathrm{CH}_{2}$ bend and $\mathrm{C}-\mathrm{H}$ bend ${ }^{12,13}$. Polyethylene terephthalate was found in the samples of branded water bottles, Chembarambakkam and Kovur. The N-H stretching around $3442 \mathrm{~cm}^{-1}, 2942 \mathrm{CH}_{2}$ asymmetric and symmetric stretch and 2883, $\mathrm{C}=\mathrm{O}$ stretch around $1654 \mathrm{~cm}^{-1}, \mathrm{NH}$ bend and $\mathrm{CH}$ stretch around $1581 \mathrm{~cm}^{-1}$ and $1226 \mathrm{~cm}^{-1}$ respectively, confirms the 


\begin{tabular}{lcl}
\hline Sample Id & $\begin{array}{c}\text { No. of } \\
\text { particles/litre }\end{array}$ & \multicolumn{1}{c}{ Factors causing contamination } \\
\hline $\begin{array}{c}\text { Surface water } \\
\text { M }\end{array}$ & 11 & $\begin{array}{l}\text { Fishing, floods, transportation and human activity }{ }^{17,19} . \\
\text { Dumping of household and various industrial plastic } \text { waste }^{17} .\end{array}$ \\
CL & 9 & \\
Groundwater & & ${\text { Located in the canal bed of River Cooum, Chennai }{ }^{17} .}^{17}$. \\
PP & 7 & Dumping yard for solid waste $^{15}$. \\
P & 5 & Urbanization $^{10}$. \\
K & 4 & \\
Commercial drinking water & \\
C & 6 & Improper purification system and degradation of plastic parts $^{11}$ \\
B1 & 5 & \\
B2 & 5 & \\
B3 & 5 & \\
B4 & 5 & \\
B5 & 2 & \\
\hline
\end{tabular}

Figure 5. Factors causing microplastic contamination.

Table 2. Presence of heavy metals adsorbed on the surface of microplastics

\begin{tabular}{|c|c|c|c|c|c|c|c|c|c|c|c|c|c|c|c|}
\hline Sample Id & $\mathrm{C}$ & $\mathrm{O}$ & $\mathrm{Na}$ & $\mathrm{Mg}$ & $\mathrm{Al}$ & $\mathrm{Si}$ & $\mathrm{Cl}$ & K & $\mathrm{Ca}$ & S & $\mathrm{Rn}$ & $\mathrm{Cr}$ & $\mathrm{T} 1$ & $\mathrm{Ba}$ & Mo \\
\hline \multicolumn{16}{|c|}{ Surface water } \\
\hline M & $\checkmark$ & $\checkmark$ & $\checkmark$ & $\checkmark$ & $\checkmark$ & $\checkmark$ & $\checkmark$ & $\checkmark$ & $\checkmark$ & & & & & & \\
\hline $\mathrm{CL}$ & & $\checkmark$ & $\checkmark$ & & $\checkmark$ & $\checkmark$ & $\checkmark$ & $\checkmark$ & $\checkmark$ & & & & & & \\
\hline \multicolumn{16}{|c|}{ Groundwater } \\
\hline PP & & $\checkmark$ & $\checkmark$ & $\checkmark$ & $\checkmark$ & $\checkmark$ & & $\checkmark$ & $\checkmark$ & & $\checkmark$ & $\checkmark$ & $\checkmark$ & $\checkmark$ & \\
\hline $\mathrm{P}$ & & $\checkmark$ & $\checkmark$ & & $\checkmark$ & $\checkmark$ & $\checkmark$ & $\checkmark$ & $\checkmark$ & & & & & & $\checkmark$ \\
\hline $\mathrm{K}$ & & $\checkmark$ & $\checkmark$ & $\checkmark$ & $\checkmark$ & $\checkmark$ & & & $\checkmark$ & & $\checkmark$ & & & & \\
\hline \multicolumn{16}{|c|}{ Commercial drinking water } \\
\hline $\mathrm{C}$ & $\checkmark$ & $\checkmark$ & $\checkmark$ & $\checkmark$ & $\checkmark$ & $\checkmark$ & $\checkmark$ & $\checkmark$ & $\checkmark$ & $\checkmark$ & & & & & \\
\hline B1 & $\checkmark$ & $\checkmark$ & $\checkmark$ & $\checkmark$ & $\checkmark$ & $\checkmark$ & $\checkmark$ & $\checkmark$ & $\checkmark$ & & & & & & \\
\hline B2 & $\checkmark$ & $\checkmark$ & $\checkmark$ & $\checkmark$ & $\checkmark$ & $\checkmark$ & $\checkmark$ & $\checkmark$ & $\checkmark$ & & & & & & \\
\hline B3 & $\checkmark$ & $\checkmark$ & $\checkmark$ & $\checkmark$ & $\checkmark$ & $\checkmark$ & $\checkmark$ & $\checkmark$ & $\checkmark$ & & & & & & \\
\hline B4 & $\checkmark$ & $\checkmark$ & $\checkmark$ & & $\checkmark$ & $\checkmark$ & $\checkmark$ & $\checkmark$ & $\checkmark$ & & & & & & \\
\hline B5 & $\checkmark$ & $\checkmark$ & $\checkmark$ & $\checkmark$ & $\checkmark$ & $\checkmark$ & $\checkmark$ & $\checkmark$ & $\checkmark$ & & & & & & \\
\hline
\end{tabular}

presence of polyamide ${ }^{12,13}$. Polyamide was present in seawater, Pallikaranai, Pallipattu and can water. Table 1 depicts the nature of microplastics and their confirmation.

SEM-EDX shows the morphology of microplastics and the presence of chemical elements. Elements such as sodium, magnesium, potassium, aluminium, silica, calcium, chlorine and oxygen adhere to the surface of microplastics. Carbon indicates the presence of polymer materials $^{14}$. Heavy metals such as ruthenium, thallium, barium and chromium present in the Pallipattu sample have been contributed by River Cooum. Molybdenum was found in Pallikaranai sample due to the large sewage treatment plant located around the region ${ }^{15}$. Ruthenium and thallium present in Kovur groundwater sample were due to urbanization ${ }^{10}$. Table 2 lists the heavy metals adsorbed on the surface of microplastics.

In India, this is the first report to study the occurrence of microplastics in drinking water sources. The reason for the occurrence of microplastics in water is due to the immense usage of plastics, and there is no proper waste management system. As microplastics are consumed by humans from drinking water, further studies are mandatory to understand the impact of microplastics on humans. For controlling microplastic pollution, the use of plastics must be reduced, or they must be recycled and reused. Proper waste management system and drinking water purification process have to be implemented for the removal of microplastics.

1. Cole, M., Lindeque, P., Halsband, C. and Galloway, T. S., Microplastics as contaminants in the marine environment: a review. Mar. Pollut. Bull., 2011, 62, 2588-2597.

2. Karami, A., Golieskardi, A., Ho, B. Y., Larat, V. and Salamatinia, B., Microplastics in eviscerated flesh and excised organs of dried fish. Sci. Rep., 2017, 7, 1-9.

3. Sruthy, S. and Ramasamy, E. V., Microplastic pollution in Vembanad Lake, Kerala, India: the first report of microplastics in lake and estuarine sediments in India. Environ. Pollut., 2017, 222, $315-322$. 
4. Veerasingam, S., Saha, M., Suneel, V., Vethamony, P., Rodrigues, A. C., Bhattacharyya, S. and Naik, B. G., Characteristics, seasonal distribution and surface degradation features of microplastic pellets along the Goa Coast, India. Chemosphere, 2016, 159, 496505

5. Veerasingam, S., Mugilarasan, M., Venkatachalapathy, R. and Vethamony, P., Influence of 2015 flood on the distribution and occurrence of microplastic pellets along the Chennai coast, India. Mar. Pollut. Bull., 2016, 109, 196-204.

6. Vidyasakar, A. et al., Macrodebris and microplastic distribution in the beaches of Rameswaram Coral Island, Gulf of Mannar, southeast coast of India: a first report. Mar. Pollut. Bull., 2018, 137, 610-616.

7. Khalik, W. M. A. W. M., Ibrahim, Y. S., Anuar, S. T., Govindasamy, S. and Baharuddin, N. F., Microplastics analysis in Malaysian marine waters: a field study of Kuala Nerus and Kuantan. Mar. Pollut. Bull., 2018, 135, 451-457.

8. Mintenig, S. M., Loder, M. G. J., Primpke, S. and Gerdts, G., Low numbers of microplastics detected in drinking water from groundwater sources. Sci. Total Environ., 2019, 648, 631-635.

9. Zbyszewski, M. and Corcoran, P. L., Distribution and degradation of fresh water plastic particles along the beaches of Lake Huron, Canada. Water Air Soil Pollut., 2011, 220, 365-372.

10. Zhao, S., Zhu, L. and Li, D., Microplastic in three urban estuaries, China. Environ. Pollut., 2015, 206, 597-604.

11. Schymanski, D., Goldbeck, C., Humpf, H. U. and Furst, P., Analysis of microplastics in water by micro-Raman spectroscopy: release of plastic particles from different packaging into mineral water. Water Res., 2018, 129, 154-162.

12. Asensio, R. C., Moya, M. S. A., Roja, J. M. D. L. and Gomez, M., Analytical characterization of polymers used in conservation and restoration by ATR-FTIR spectroscopy. Anal. Bioanal. Chem., 2009, 395, 2081-2096.

13. Jung, M. R. et al., Validation of ATR FT-IR to identify polymers of plastic marine debris, including those ingested by marine organisms. Mar. Pollut. Bull., 2018, 127, 704-716.

14. Fries, E., Dekiff, J. H., Willmeyer, J., Nuelle, M. T., Ebert, M. and Remy, D., Identification of polymer types and additives in marine microplastic particles using pyrolysis-GC/MS and scanning electron microscopy. Environ. Sci.: Process. Impacts, 2013, 15, 1949 1956.

15. Kang, H. J., Park, H. J., Kwon, O. K., Lee, W. S., Jeong, D. H., $\mathrm{Ju}, \mathrm{B}$. K. and Kwon, J. H., Occurrence of microplastics in municipal sewage treatment plants: a review. Environ. Health Toxicol., 2018, 33, 1-8

16. Mugilarasan, M., Venkatachalapathy, R., Sharmila, N. and Gurumoorthi, K., Occurrence of microplastic resin pellets from Chennai and Tinnakkara Island: towards the establishment of background level for plastic pollution. Indian J. Mar. Sci., 2017, 46, 1210-1212.

17. Sathish, N., Jeyasanta, K. I. and Patterson, J., Abundance, characteristics and surface degradation features of microplastics in beach sediments of five coastal areas in Tamil Nadu, India. Mar. Pollut. Bull., 2019, 142, 112-118.

18. www.arcgis.com

19. Browne, M. A., Crump, P., Niven, S. J., Teuten, E., Tonkin, A., Galloway, T. and Thompson, R., Accumulation of microplastic on shorelines worldwide: sources and sinks. Environ. Sci. Technol., 2011, 415, 9175-9179.

ACKNOWLEDGEMENT. This study was supported by the University Grants Commission, New Delhi.

Received 7 June 2019; revised accepted 6 August 2019

doi: $10.18520 / \mathrm{cs} / \mathrm{v} 117 / \mathrm{i} 11 / 1879-1885$

\section{Transcriptomic analysis of chilling-} treated tobacco (Nicotiana tabacum) leaves reveals chilling-induced lignin biosynthetic pathways

\section{PeiLu Zhou ${ }^{1,2}$, QiYao Li ${ }^{1}$, Guang Liang Liu ${ }^{1}$, Na Xu ${ }^{1}$, Yin Ju Yang ${ }^{1}$, Yi Wang ${ }^{1}$, Wen Long Zeng ${ }^{3}$, Shu Sheng Wang ${ }^{1}$ and Ai Guo Chen ${ }^{1, *}$}

${ }^{1}$ Key Laboratory of Tobacco Biology and Processing, Ministry of Agriculture, Tobacco Research Institute of Chinese Academy of Agricultural Sciences, Qingdao 266101, People's Republic of China

${ }^{2}$ Tianjin Agricultural University, Tianjin 300384 , People's Republic of China

${ }^{3}$ Longyan Tobacco Agricultural Science Institute, Longyan,

Fujian 364000, People's Republic of China

Chilling stress is one of the most important environmental stresses for chilling-sensitive species. The present study conducted RNA-Seq and WGCNA analysis to clarify the correlation patterns among genes of different treatments in tobacco (Nicotiana tabacum). A total of 10,355 DEGs were found in chilling treatment relative to control treatment. Additionally, functional annotations revealed that 48 genes were found to be specifically expressed in lignin biosynthesis pathway in tobacco seedlings under chilling stress. Our results revealed that the biosynthesis of caffeoyl-CoA was regulated by $\mathrm{HCT}$ and $\mathrm{C} 3 \mathrm{H}$. Furthermore, the G-type lignin biosynthesis branch was enhanced under low temperature, which contributed to an increase in lignin content and changes in lignin composition, indicating that G-type lignin may play an important role in tobacco's resistance to chilling stress.

Keywords: Chilling stress, lignin biosynthesis, Nicotiana tabacum, transcriptomic, WGCNA.

Chilling stress is one of the environmental factors that restrict plant growth and geographical distribution. Plants have evolved a number of sophisticated mechanisms to rapidly respond to changes in the environment and different types of defense mechanisms that protect plants from chilling stress. The synthesis of compounds in the phenylpropanoid pathway (Supplementary Figure 1) fulfills a wide range of such functions, including plant development and interactions with the environment ${ }^{1}$.

The phenylpropanoid metabolic pathway mainly starts with phenylalanine (Supplementary Figure 1) and provides the precursors of lignin, which is quantitatively the second most common biopolymer on Earth, following cellulose. The intermediates and products of the phenylpropanoid pathway regulate tobacco growth and

*For correspondence. (e-mail: chenaiguo@caas.cn) 